\title{
FKBP51 promotes migration and invasion of papillary thyroid carcinoma through NF-kB-dependent epithelial-to-mesenchymal transition
}

\author{
YING GAO $^{1,2}$, ELHAM ELAMIN ${ }^{1}$, RONGFANG ZHOU ${ }^{1}$, HUILI YAN $^{3}$, SHUANG LIU $^{1}$, \\ SHENGNAN HU ${ }^{1}$, JING DONG ${ }^{1}$, MUYUN WEI $^{1}$, LINYING SUN $^{1}$ and YUERAN ZHAO ${ }^{1}$ \\ ${ }^{1}$ Department of Central Lab, Shandong Provincial Hospital Affiliated to Shandong University, Shandong, Jinan 250021; \\ ${ }^{2}$ Department of Laboratory Medicine, Shandong Qianfoshan Hospital, Shandong University, Shandong, Jinan 250014; \\ ${ }^{3}$ Department of Medicine and Life Science, University of Jinan-Shandong Academy of Medical Sciences, \\ Shandong, Jinan 250062, P.R. China
}

Received November 10, 2017; Accepted August 3, 2018

DOI: $10.3892 / \mathrm{ol} .2018 .9517$

\begin{abstract}
FK506-binding protein 51 (FKBP51) is a member of the immunophilin family, with relevant roles in multiple signaling pathways, tumorigenesis and chemoresistance. However, the function of FKBP51 in papillary thyroid carcinoma (PTC) remains largely unknown. In the present study, increased FKBP51 expression was detected in PTC tissues as compared with adjacent normal tissues, and the expression level was associated with clinical tumor, node and metastasis stage. Using FKBP51-overexpressing K1 cells and FKBP51-knockdown TPC-1 cells, both human PTC cell lines, it was identified that FKBP51 promoted the migration and invasion of PTC, without affecting cell proliferation. Further investigation revealed that FKBP51 activated the $\mathrm{NF}-\kappa \mathrm{B}$ pathway and epithelial-to-mesenchymal transition (EMT) genes, and EMT was suppressed when NF- $\mathrm{BB}$ was inhibited. It was also assessed whether FKBP51 promoted the formation of cytoskeleton to promote migration and invasion of PTC using a tubulin tracker; however, no evidence of such an effect was observed. These results suggested that FKBP51 promotes migration and invasion through $\mathrm{NF}-\kappa \mathrm{B}$-dependent EMT.
\end{abstract}

\section{Introduction}

FK506-binding proteins (FKBPs) belong to the family of immunophilins, which may bind to immunosuppressant drugs (1). It contains a 3-unit tetratricopeptide repeat structural motif connected to a domain that mediates enzymatic function

Correspondence to: Professor Yueran Zhao, Department of Central Lab, Shandong Provincial Hospital Affiliated to Shandong University, 544 Jingsi Road, Shandong, Jinan 250021, P.R. China E-mail:yrzhao@sdu.edu.cn

Key words: migration, invasion, epithelial-to-mesenchymal and peptidyl prolyl isomerase activity. FKBP51 interacts with glucocorticoid, androgen, estrogen, progestin and mineralocorticoid receptors (2-7) through a number of components of the molecular chaperone machinery, including heat shock protein 90. FKBP51 has been identified to be upregulated or downregulated in multiple types of cancer and to be associated with cell motility and invasion, for instance, Leach et al (8) identified that FKBP51 is increased in prostate cancer cells compared with normal prostate epithelial cells and improves the ability of stromal androgen receptor to predict prostate cancer-specific mortality. Hou et al (9) reported that low levels of FKBP51 promote pancreatic tumor growth. FKBP51 may promote cancer, including melanoma, through the nuclear factor $(\mathrm{NF})-\kappa \mathrm{B}$ pathway $(10,11)$ and suppress cancer through the phosphatidylinositol-4,5-bisphosphate 3 kinase/protein kinase B (AKT) signaling pathway $(12,13)$. It has been demonstrated that the activation of NF- $\mathrm{NB}$ contributes to growth (14) and aggressiveness of papillary thyroid carcinoma, and lymph node metastases in papillary thyroid carcinoma (PTC) are significantly correlated with NF- $\kappa \mathrm{B}$ levels (15). Recently, studies have demonstrated that FKBP51 serves an important role in epithelial-mesenchymal transition (EMT) (16-18). EMT refers to the biological process by which epithelial cells are transformed into mesenchymal phenotype cells by certain procedures. In this procedure, expression of epithelial cell characteristic proteins, including adhesion molecule E-cadherin, decreased and cytokeratin cytoskeleton changed into vimentin skeleton (19). In colorectal carcinoma, Rotoli $\mathrm{D}$ was determined to have increased microvessel density and tumor-associated macrophages in connective tissue surrounding FKBP51 positive lesions (16).

The morbidity rate of PTC is increasing worldwide $(20,21)$. Surgery is the primary treatment for PTC. The prevalence of PTC is nearly 3 times higher in females than in males (22). This sex difference suggests that growth and progression of PTC may be influenced by female sex hormones, and it has been demonstrated that estrogen and progesterone receptors are more strongly expressed in thyroid hyperplasia diseases than in normal thyroid tissue (23). 
As FKBP51 regulates the activity of sex-hormone receptors and correlates with a number of types of cancer, and PTC may be a sex hormone-associated cancer, in the present study, the function of FKBP51 in PTC was investigated.

\section{Materials and methods}

Materials. The human PTC cell lines K1 and TPC-1 were purchased from the Cell Bank of the Chinese Academy of Sciences (Shanghai, China). RPMI-1640, Dulbecco's modified Eagle's medium and fetal bovine serum (FBS) were purchased from Invitrogen (Thermo Fisher Scientific, Inc., Waltham, MA, USA). Anti-FKBP51 (ab46002) used in immunohistochemistry (IHC), anti-I $\mathrm{B} \alpha$ (ab32518), anti-N-cadherin (ab76011), anti-Vimentin (ab92547), anti- $\beta$-catenin (ab32572) and anti-MMP9 (ab76003) were purchased from Abcam (Cambridge, UK). Anti-p65 (sc-8008), anti-FKBP51 (sc-13983), anti-GAPDH (sc-47724), anti- $\alpha$-tubulin (sc-53646), secondary antibody anti-mouse IgG-horseradish peroxidase (HRP; sc-516102) and anti-rabbit IgG-HRP (sc-2372) used in western blotting were purchased from Santa Cruz Biotechnology, Inc. (Dallas, TX, USA). Anti-TGF- $\beta 1$ (3709) and anti-histone 3 (12164) was purchased from Cell Signaling Technology (Danvers, MA, USA). Ammonium pyrrolidine dithiocarbamate (PDTC; T3147) was purchased from Target Molecule Corp. (Wellesley Hills, MA, USA).

IHC. IHC was used to detect expression of FKBP51. Thyroid tissue microarrays including 31 PTC tissues and 41 adjacent normal tissues were purchased from Shanxi Alena Biotechnology (Shanxi, China). Following staining with the Elivision ${ }^{\mathrm{TM}}$ plus kit (cat. no. 9902; Maxim Biotech, Inc., Rockville, MD, USA), according to the manufacturer's protocols, the specimens were incubated overnight with primary antibody (anti-FKBP51; 1:50 dilution) at $4^{\circ} \mathrm{C}$, and washed with $0.1 \%$ Tween-20 PBS for 5 min 3 times. Subsequently, polymer enhancer (Elivision ${ }^{\mathrm{TM}}$ plus kit), which assists horse radish peroxidase-anti-rabbit polymer (Elivision $^{\mathrm{TM}}$ plus kit) to combine with primary antibodies, was added and incubated for $20 \mathrm{~min}$ at room temperature, and then wash with $0.1 \%$ Tween-20 PBS for $5 \mathrm{~min}$ 3 times. Following this, the horse radish peroxidase-labeled anti-rabbit polymer (Elivision ${ }^{\mathrm{TM}}$ plus kit) was added and incubated at room temperature for $30 \mathrm{~min}$, and then washed with $0.1 \%$ Tween-20 PBS for 5 min 3 times. Additionally, the specimens were stained with diaminobenzidine solution (DAB-0031/1031; Maxim Biotech, Inc.) for 5 min at room temperature, and distilled water was used to rinse the specimens and stop the coloration.

The expression of FKBP51 was scored by two professional pathologists as follows: $1+, 1-25 \%$ of positive tumor cells; $2+, 25-50 \% ; 3+, 50-74 \%$; and $4+, \geq 75 \%$. 0, negative staining; 1+, light brown; $2+$, brown; $3+$, dark brown. The total score was between $0-12$ and was calculated as the positive percentage score multiplied by the intensity score. FKBP51 expression levels were ranked into four grades according to the total score: $0,-; 1-4,+; 5-8,++; 9-12,+++$.

The clinical stage of papillary thyroid carcinoma was guided by American Joint Committee on Cancer (24).
Lentivirus and plasmid transfection. The human FKBP51 gene sequence was retrieved from the NCBI gene bank (https:/www.ncbi.nlm.nih.gov/nuccore/U71321.1) and restriction enzymes were used to cut appropriate sequences as the target gene and amplified through polymerase chain reaction [The target gene from chemical synthesis was denatured into a single strand at a high temperature $\sim 95^{\circ} \mathrm{C}$, and the single nucleotide was combined into the target gene from the $3^{\prime}$ end of the primer (FKBP51: Sense, 5'-AAAAGGCCAAGGAGC ACAAC-3' and antisense 5'-TTGAGGAGGGGCCGA194 GTTC-3') to synthesize a new complementary strand of DNA with a heat-resistant DNA polymerase (Takara Bio, Inc., Otsu, Japan). The full thermocycling conditions can be simplified into the following steps: Pre-denaturation $\left(95^{\circ} \mathrm{C}\right.$ for $\left.30 \mathrm{sec}\right)$, reaction cycles $\left(95^{\circ} \mathrm{C}\right.$ for $5 \mathrm{sec}$ and $60^{\circ} \mathrm{C}$ for $\left.30 \mathrm{sec}\right)$, melting $\left(95^{\circ} \mathrm{C}\right.$ for $5 \mathrm{sec}$ and $60^{\circ} \mathrm{C}$ for $\left.1 \mathrm{~min}\right)$ and cooling $\left(50^{\circ} \mathrm{C}\right.$ for $30 \mathrm{sec})$. Subsequently, the FKBP51 cDNA was cloned into the GV303 lentiviral expression vector. All this process was conducted by Shanghai GeneChem (Shanghai GeneChem, Co., Ltd., Shanghai, China). Plasmids encoding human FKBP51 shRNA (SC-35380-SH) and scramble shRNA were purchased from Santa Cruz Biotechnology, Inc. K1 cells were seeded in a 96 -well plate $\left(5 \times 10^{3}\right.$ cells/well $)$ overnight. Then, the cells were infected with $1 \times 10^{6}$ units of the recombinant lentiviral vector carrying wild-type human FKBP51 (concentration, $2 \times 10^{8} \mathrm{U} / \mathrm{ml}$ ) or randomized flanking sequences (concentration, $1 \times 10^{9} \mathrm{U} / \mathrm{ml}$ ) as a control under the condition of the Polybrene $(5 \mu \mathrm{g} / \mathrm{ml})$ as the transfection reagent (Shanghai GeneChem, Co., Ltd.). After 8-12 h, the virus mixture was exchanged for fresh RPMI-1640 complete medium. Green fluorescent protein (GFP)-positive infected cells were detected by fluorescence microscopy (x10) at $72 \mathrm{~h}$ after transfection. TPC-1 cells were seeded in a 6 -well plate $\left(2 \times 10^{5}\right.$ cells/well $)$. The next day, shR-FKBP51 and shR-vec plasmids were added to the cells, and 5-7 $\mathrm{h}$ later, the mixture was changed into fresh medium containing $20 \%$ FBS. After $48 \mathrm{~h}$, transfected cells were selected using puromycin $(12 \mu \mathrm{g} / \mathrm{ml})$. Subsequent experiments were performed following confirmation of the efficiency of infection ( $72 \mathrm{~h}$ after infection).

Proliferation assay. FKBP51-overexpressing or knockdown cells and control cells were digested with trypsin and then seeded into 96 -well plates $\left(5 \times 10^{3}\right.$ cells/well) and incubated at $37^{\circ} \mathrm{C}$ under $5 \% \mathrm{CO}_{2}$. Following incubation for 24,48 and $72 \mathrm{~h}, 10 \mu \mathrm{l}$ of cell counting kit-8 and $90 \mu \mathrm{l}$ of RPMI-1640 fresh medium were added into each well. Following incubation at $37^{\circ} \mathrm{C}$ in an atmosphere containing $5 \% \mathrm{CO}_{2}$ for $1 \mathrm{~h}$, the absorbance was measured at $450 \mathrm{~nm}$ using a SpectraMax M2 instrument. All experiments were performed in triplicate.

Migration and invasion assays. In total, $2 \times 10^{5} \mathrm{~K} 1$ cells or $3 \times 10^{4}$ TPC- 1 cells in serum-free RPMI-1640 medium were added into Transwell upper chambers with 8 -mm pore-size membranes, and complete medium was added to the lower chambers. To detect cell invasion ability, membranes were coated with Matrigel (diluted 1:6 in 1x PBS; BD Biosciences, Franklin Lakes, NJ, USA). The plate was incubated at $37^{\circ} \mathrm{C}$ in an atmosphere containing $5 \% \mathrm{CO}_{2}$ for $24 \mathrm{~h}$. Cells on the upper membrane surface were removed using cotton swabs and washed with 1x PBS, and the cells attached to the bottom 
surface of the membrane were stained using crystal violet at room temperature for $15 \mathrm{~min}$. Images (x20) were captured using a Nikon fluorescence microscope (Nikon Corporation, Tokyo, Japan).

Western blotting. Cells were harvested and total protein was extracted using radioimmunoprecipitation assay buffer (Thermo Fisher Scientific,Inc.). The protein concentration was determined using a bicinchoninic acid assay. A total of $30 \mu \mathrm{g}$ of protein was separated via 10\% SDS-PAGE and transferred onto polyvinylidene difluoride membranes (EMD Millipore, Billerica, MA, USA). Following blocking for $1 \mathrm{~h}$ with $5 \%$ nonfat milk (Yili Dairy Corporation Group, Co., Ltd., Hohhot, China) diluted with PBS, the membranes were incubated with the following primary antibodies at $4^{\circ} \mathrm{C}$ overnight: Anti-FKBP51 $(1: 1,000)$, anti-p65 (1:250), anti-IкB $\alpha(1: 1,000)$, anti-TGF- $\beta 1$ (1:1,000), anti-N-cadherin (1:1,000), Vimentin $(1: 1,000)$, anti- $\beta$-catenin $(1: 1,000)$ and anti-MMP9 $(1: 1,000)$. Following washing three times with $1 \mathrm{X}$ TBS with Tween-20, the membranes were incubated with horseradish peroxidase-conjugated secondary antibodies $(1: 1,000)$ for $1 \mathrm{~h}$ at room temperature and then washed three times with 1X TBS with Tween-20. The resulting signal was detected using Scion Image software version 4.03 (Scion Corporation, Frederick, MD, USA), and the quantity of protein was normalized to that of GAPDH $(1: 1,000)$, histone $3(1: 1,000)$, or $\alpha$-tubulin $(1: 1,000)$ (for normalization to total protein, nuclear protein, or cytoplasmic protein, respectively).

Immunofluorescence microscopy. Cells on a slide were fixed with $3.7 \%$ formaldehyde for $10 \mathrm{~min}$ and washed with PBS containing $0.1 \%$ Triton X-100 twice. Tubulin-Tracker Red (Beyotime Institute of Biotechnology, Haimen, China) was diluted 1:250 in PBS containing 5\% bovine serum albumin (Beijing Solarbio Science \& Technology Co., Ltd., Beijing, China) and $0.1 \%$ Triton X-100, and the slides were incubated with this solution for $30 \mathrm{~min}$ at room temperature. The slides were then washed three times with PBS for 5 min each.

PDTC inhibition test. PDTC powder was dissolved in dimethyl sulfoxide (DMSO) as a storage solution $(20 \mathrm{mM})$, and the working fluid concentration was $20 \mu \mathrm{M}$. In the Transwell test, $0.2 \mu \mathrm{l}$ PDTC storage solution was added into $200 \mu \mathrm{l}$ cell suspension in the upper chambers and $0.2 \mu \mathrm{l}$ DMSO was added in the control group. Migrated and invaded cells were counted after $24 \mathrm{~h}$. In the western blot assay, FKBP51-overexpressing $\mathrm{K} 1$ cells were seeded into 6 -well plate $\left(1 \times 10^{6}\right.$ cells/well). The following day, $2 \mu$ PDTC storage solution was added into $2 \mathrm{ml}$ fresh RPMI-1640 medium in the plate and $2 \mu \mathrm{l}$ DMSO was added in the control group. The protein of the two cell groups were extracted after culturing for $24 \mathrm{~h}$ at $37^{\circ} \mathrm{C}$ in an atmosphere containing $5 \% \mathrm{CO}_{2}$. The migration/invasion and western blotting assays were similar to that aforementioned, with the difference being whether PDTC or DMSO was added.

Statistical analysis. All results were analyzed using SPSS software (version 20.0; IBM Corp., Armonk, NY, USA) and data are presented as the mean \pm standard error of at least three independent experiments. The differences between two groups were evaluated using Student's t-test. Differences among multiple groups were assessed using one-way analysis of variance and the Student's Newman Keuls-q test was used for post-hoc analysis. $\mathrm{P}<0.05$ was considered to indicate a statistically significant difference.

\section{Results}

FKBP51 is highly expressed in PTC. IHC analysis revealed higher FKBP51 expression in PTC than in the adjacent normal tissues. Furthermore, the FKBP51 expression level was associated with clinical tumor, node and metastasis (TNM) stage, with stronger FKBP51 expression indicating poorer TNM stage (Fig. 1; Table I).

FKBP51 promotes migration and invasion of PTC without affecting cell proliferation. FKBP51-overexpressing and control K1 cells were successfully constructed, alongside FKBP51-knockdown and control TPC-1 cells (Fig. 2A). To determine the effect of FKBP51 on PTC cell migration and invasion, a transwell assay was performed. Fig. $2 \mathrm{~B}$ presents that FKBP51 overexpression promoted cell migration and invasion as compared with the control group in $\mathrm{K} 1$ cells. The counts of migrated cells were $210 \pm 61.2$ and 102.0 $\pm 9.1(\mathrm{P}<0.05)$, and those of invaded cells were $75.3 \pm 11.5$ and $48.8 \pm 6.2(\mathrm{P}<0.05)$, in overexpressing and control cells, respectively. FKBP51 knockdown inhibited cell migration and invasion in TPC-1 cells as compared with the control group. The counts of migrated cells were $158.5 \pm 11.4$ and $50.25 \pm 7.4(\mathrm{P}<0.05)$, and those of invaded cells were 81.8 \pm 6.3 and $29.5 \pm 6.0(\mathrm{P}<0.05)$, respectively. There was no significant difference in proliferation between FKBP51-overexpressing and control K1 cells, and FKBP51-knockdown and control TPC-1 cells (Fig. 2C).

FKBP51 regulates the $N F-\kappa B$ pathway. The molecular mechanism underlying the promoting effect of FKBP51 on migration and invasion was investigated. The results demonstrated that FKBP51 activated the NF- $\kappa$ B pathway. The activity of the NF- $\mathrm{KB}$ pathway was investigated at the basic level and at the TNF- $\alpha$-stimulated level. Western blotting results revealed that both at the basic and the stimulated level, cytoplasmic IкB $\alpha$ and cytoplasmic P65 were decreased and nuclear P65 was increased in FKBP51-overexpressing K1 cells, while cytoplasmic IкB $\alpha$ and P65 were increased and nuclear P65 decreased in FKBP51-knockdown TPC-1 cells as compared with the control groups (Fig. 3).

Further, the NF-KB pathway inhibitor PDTC $(20 \mu \mathrm{M})$ suppressed migration and invasion of GFP-FKBP51 K1 (Fig. 4A). This confirmed that FKBP51 inhibited PTC cell migration and invasion via the NF- $\mathrm{kB}$ pathway.

FKBP51 activates $N F-\kappa B$-dependent EMT. EMT-associated protein expression was altered with FKBP51 expression level. TGF- $\beta 1, \beta$-catenin, $\mathrm{N}$-cadherin, and MMP9 were increased in FKBP51-overexpressing K1 cells, while TGF- $\beta 1$, Vimentin, $\mathrm{N}$-cadherin and MMP9 were decreased in FKBP51-knockdown TPC-1 cells, as presented in Fig. 4B. Subsequently, it was assessed whether EMT is regulated by the NF- $\mathrm{KB}$ pathway. FKBP51-overexpressing K1 cells were treated with PDTC $(20 \mu \mathrm{M})$ for $24 \mathrm{~h}$. TGF- $\beta 1, \mathrm{~N}$-cadherin, $\beta$-catenin and MMP9 were decreased as compared with control group by this treatment (Fig. 4C). 
Table I. FKBP51 expression in different patients and tissues.

\begin{tabular}{|c|c|c|c|c|c|c|}
\hline \multirow[b]{2}{*}{ Characteristics } & \multicolumn{5}{|c|}{ Expression of FKBP51 } & \multirow[b]{2}{*}{ P-value } \\
\hline & Cases & - & + & ++ & +++ & \\
\hline Group & & & & & & 0.015 \\
\hline PTC & 31 & 14 & 4 & 9 & 4 & \\
\hline Normal & 41 & 23 & 15 & 3 & 0 & \\
\hline Age & & & & & & 0.140 \\
\hline$<45$ & 46 & 27 & 11 & 6 & 2 & \\
\hline$>45$ & 26 & 11 & 7 & 5 & 3 & \\
\hline TNM & & & & & & 0.023 \\
\hline I & 19 & 11 & 4 & 3 & 1 & \\
\hline II & 9 & 2 & 1 & 5 & 1 & \\
\hline III & 2 & 1 & 0 & 1 & 0 & \\
\hline IV & 1 & 0 & 0 & 0 & 1 & \\
\hline
\end{tabular}

PTC, papillary thyroid carcinoma; FKBP51, FK506 binding protein 51.
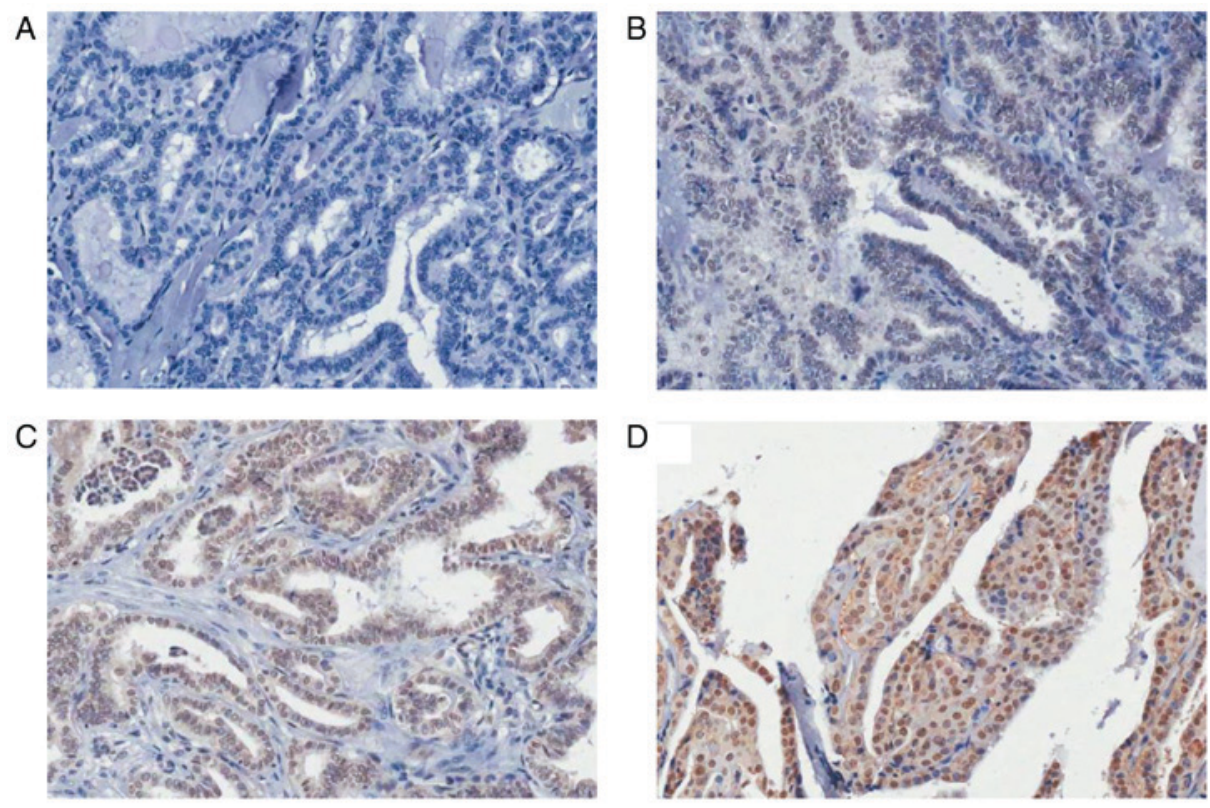

Figure 1. FK506-binding protein 51 expression level in papillary thyroid carcinoma tissues and adjacent normal tissues (magnification, x200). Representative images of tissues rated (A) -, (B),$+(\mathrm{C})++$ and $(\mathrm{D})+++$.

FKBP51 does not alter the formation of tubulin. Further, it was assessed whether FKBP51 promotes migration and invasion of PTC cells through promoting the formation of tubulin cytoskeleton, using immunofluorescence staining. No difference in fluorescent signal was observed between FKBP51-overexpressing and control K1 cells, and FKBP51-knockdown and control TPC-1 cells (Fig. 5).

\section{Discussion}

PTC accounted for $60-70 \%$ of thyroid cancer between 1992-2002 in Liaoning, China, mostly in adults aged between 20 and 50 years (25). There are numerous factors affecting PTC, including environmental factors and genetic mutations (26). However, gender is universally recognized as one of the risk factors since the occurrence is significantly higher in females than males (27). Therefore, most patient samples from the tissue microarray were female patients. PTC generally has small size and slow progression, but early metastasis may be identified (28). The underlying molecular mechanism and associated molecular markers of metastasis are not clear. Upregulation and downregulation of FKBP51 is observed in a number of human tumors. It is notable that FKBP51 is associated with the development of a variety of hormone-associated tumors, and previous studies have demonstrated that FKBP51 is overexpressed in androgen-dependent prostate cancer $(8,10)$, and decreased 

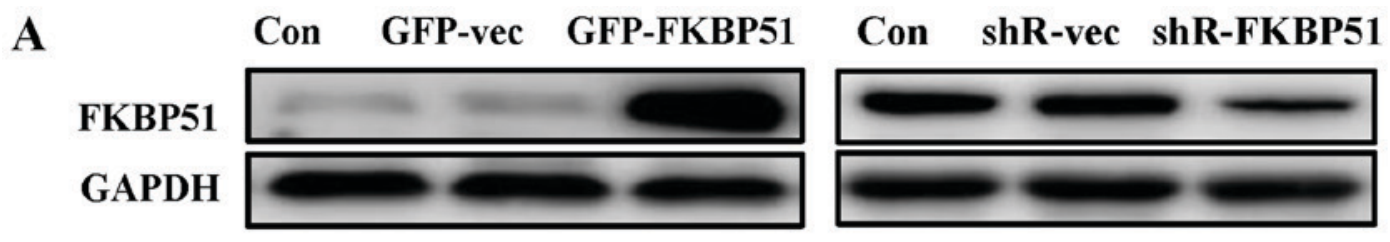

B

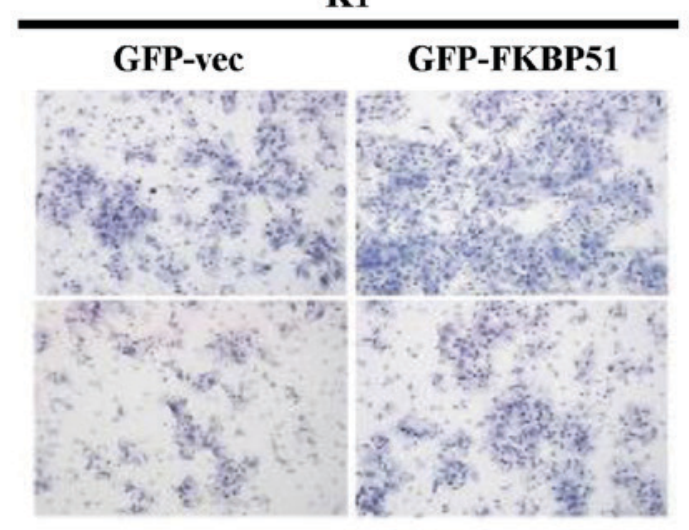

TPC-1

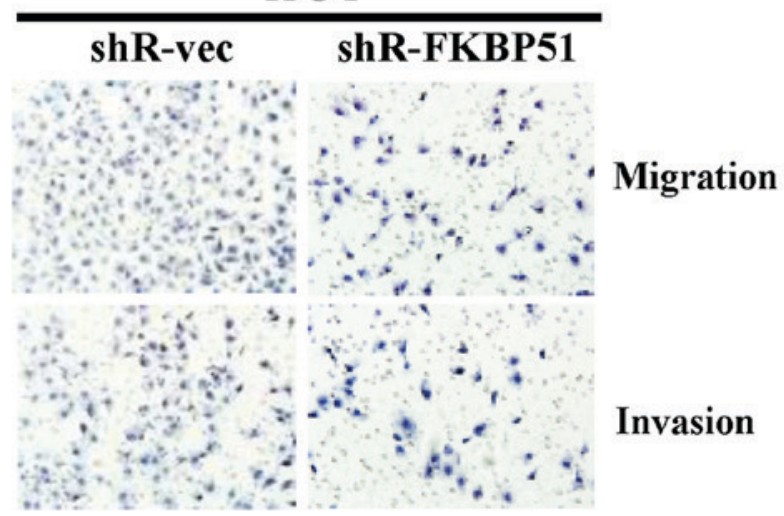

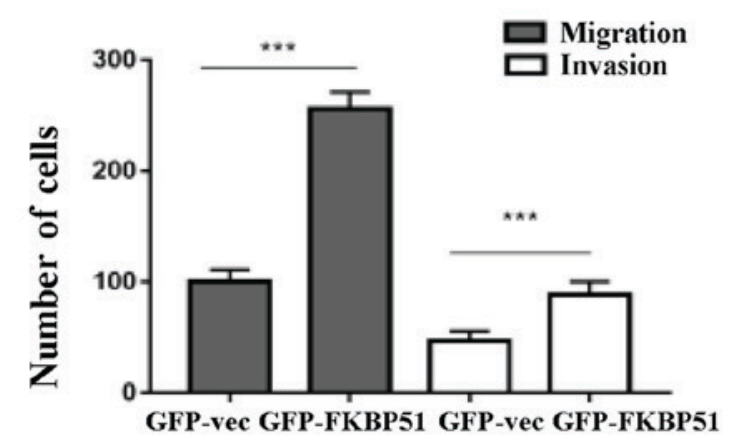
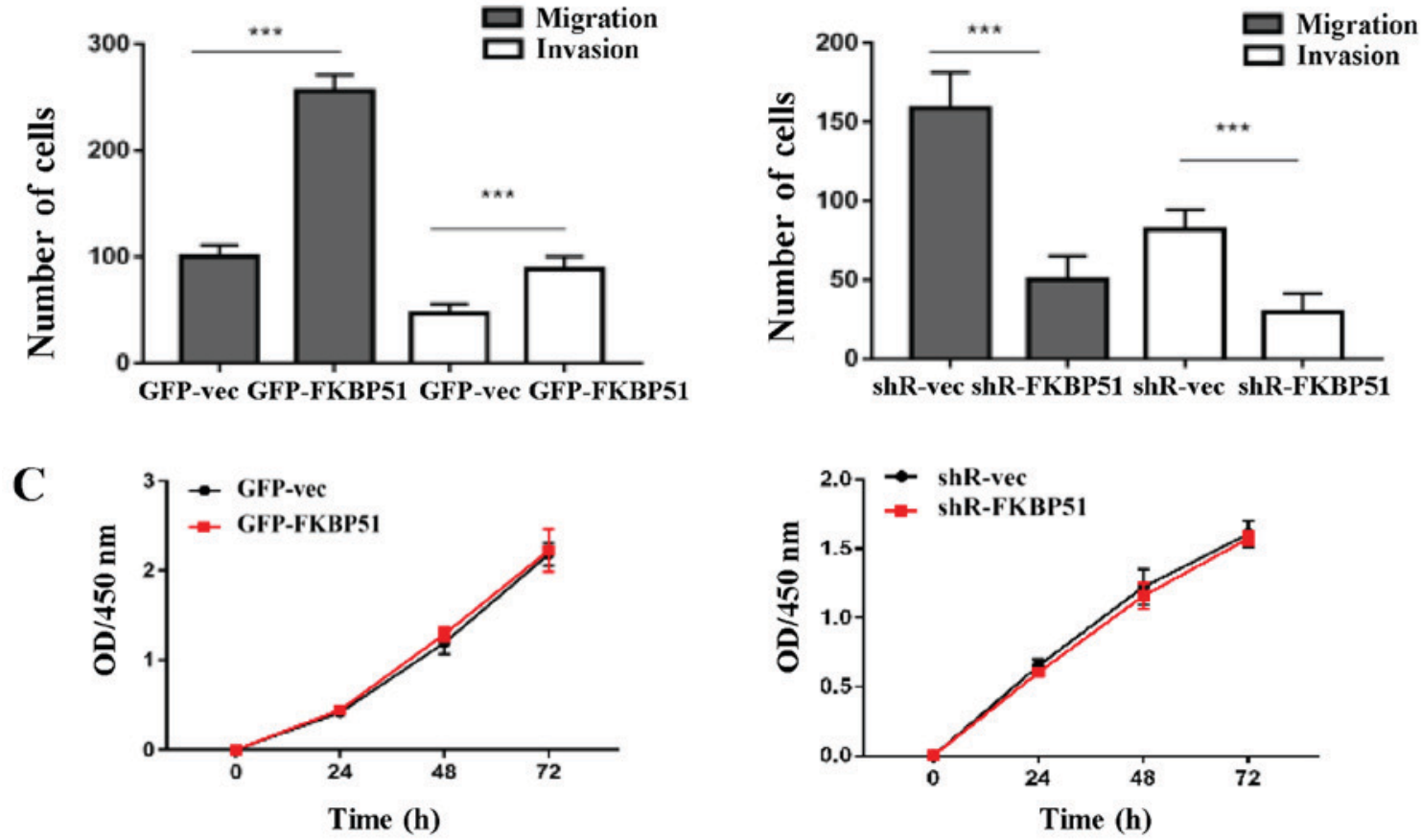

Figure 2. FKBP51 promoted cell migration and invasion of papillary thyroid carcinoma cells without affecting proliferation. (A) FKBP51 overexpressing and control K1 cells and FKBP51 knockdown and control TPC-1 cells. (B) The cells migration and invasive capacities were determined using a transwell assay. The data represent the mean \pm standard deviation of at least 3 independent experiments $\left({ }^{* * * *} \mathrm{P}<0.001\right)$. (C) Cell counting kit- 8 analysis was used to determine cell proliferation difference between FKBP51-overexpressing and the control K1 cells as well as FKBP51-knockdown and the control TPC-1 cells. The result revealed no significance ( $\mathrm{P}>0.05$ ). FKBP51, FK506 binding protein 51; GFP, green fluorescent protein; vec, vector; Con, control.

in estrogen- and progesterone-associated breast cancer (29). In the present study, the expression of FKBP51 in PTC and its clinical significance were analyzed. It was identified that FKBP51 is expressed in both PTC and adjacent tissues, however its expression was significantly higher in cancer than in adjacent normal tissues. Furthermore, the FKBP51 expression level was associated with clinical TNM stage. Thus, it is hypothesized that FKBP51 may be associated with the proliferation and metastasis of thyroid cancer.

Accumulating data have demonstrated that FKBP51 serves important functions in tumor cell growth, apoptosis, and sensitivity to radiotherapy and chemotherapy $(30,31)$. Studies have demonstrated that FKBP51 may serve a positive function in tumor progression by activating the $\mathrm{NF}-\kappa \mathrm{B}(32-34)$ pathway, or a negative function by promoting the Akt pathway through the dephosphorylation of Akt Ser473 to inhibit cell proliferation $(9,35)$. The mechanism of FKBP51 in promoting cancer cell migration and invasion is not clear. Romano et al (17) and D'Angelillo et al (18) identified that FKBP51 may promote the migration and invasion of melanoma by activating EMT-associated genes. TGF- $\beta 1$ as the key inducer of EMT not only promotes tumor cell metastasis but 


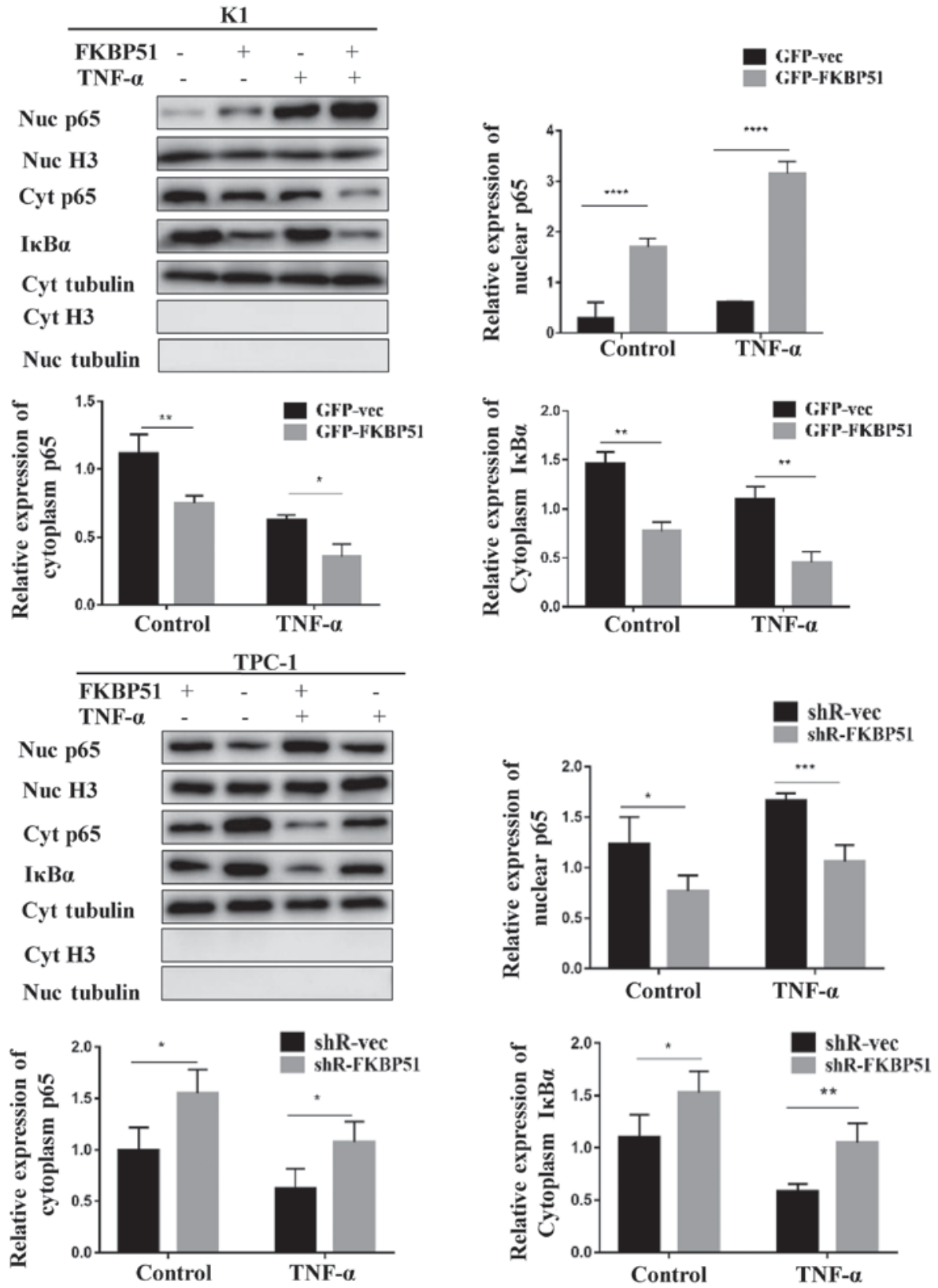

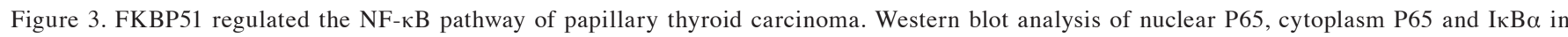
FKBP51-overexpressing and control K1 cells, and FKBP51-knockdown and control TPC-1 cells are presented. ${ }^{*} \mathrm{P}<0.05 ;{ }^{* * *} \mathrm{P}<0.01 ;{ }^{* * *} \mathrm{P}<0.001 ;{ }^{* * * * *} \mathrm{P}<0.0001$. FKBP51, FK506 binding protein 51; GFP, green fluorescent protein; vec, vector; TNF, tumor necrosis factor; Nuc, nuclear; Cyt, cytoplasmic.

also mediates liver cirrhosis (36) and renal tubulointerstitial fibrosis (37). Further, FKBP51 reportedly not only promotes the activation of EMT genes but also induces certain melanoma stem cell genes (38). Srivastava et al (39) identified that FKBP51 promotes the proliferation and migration of melanoma by mediating interleukin IL-8. Certain researchers have demonstrated that FKBP51 promotes tubulin cytoskeleton formation through the ras homolog family member A pathway to promote cell invasion (40). In the present study, K1 and TPC-1 cell lines were selected, which are commonly used in study [the K1 cell line is a GLAG-66 derivative (41)] to overexpress and knockdown FKBP51 respectively. The results demonstrated that FKBP51 did not affect cell proliferation, but significantly promoted the migration and invasion of PTC cells. To clarify the underlying mechanism of the latter observation, NF- $\mathrm{KB}$ pathway- and EMT-associated proteins were evaluated. The results revealed that both the basic and the TNF- $\alpha$-simulated activity of the NF- $\mathrm{BB}$ pathway were increased in FKBP51-overexpressing than in control cells. Similarly, EMT-associated proteins were altered in FKBP51-overexpressing K1 and FKBP51-knockdown TPC-1 cells. Subsequently, the present study aimed to evaluate whether there is an association between EMT and the NF- $\kappa B$ pathway. When the NF- $\kappa \mathrm{B}$ inhibitor PDTC was added to FKBP51-overexpressing K 1 cells for $24 \mathrm{~h}$, TGF- $\beta 1$, N-cadherin, and $\beta$-catenin and MMP9 expression were decreased. These results revealed that FKBP51 promotes migration and invasion through NF- $\kappa \mathrm{B}$ pathway-dependent EMT. This result is consistent with previous findings, for example Ying et al (42) demonstrated that induced EMT was accompanied by nuclear 

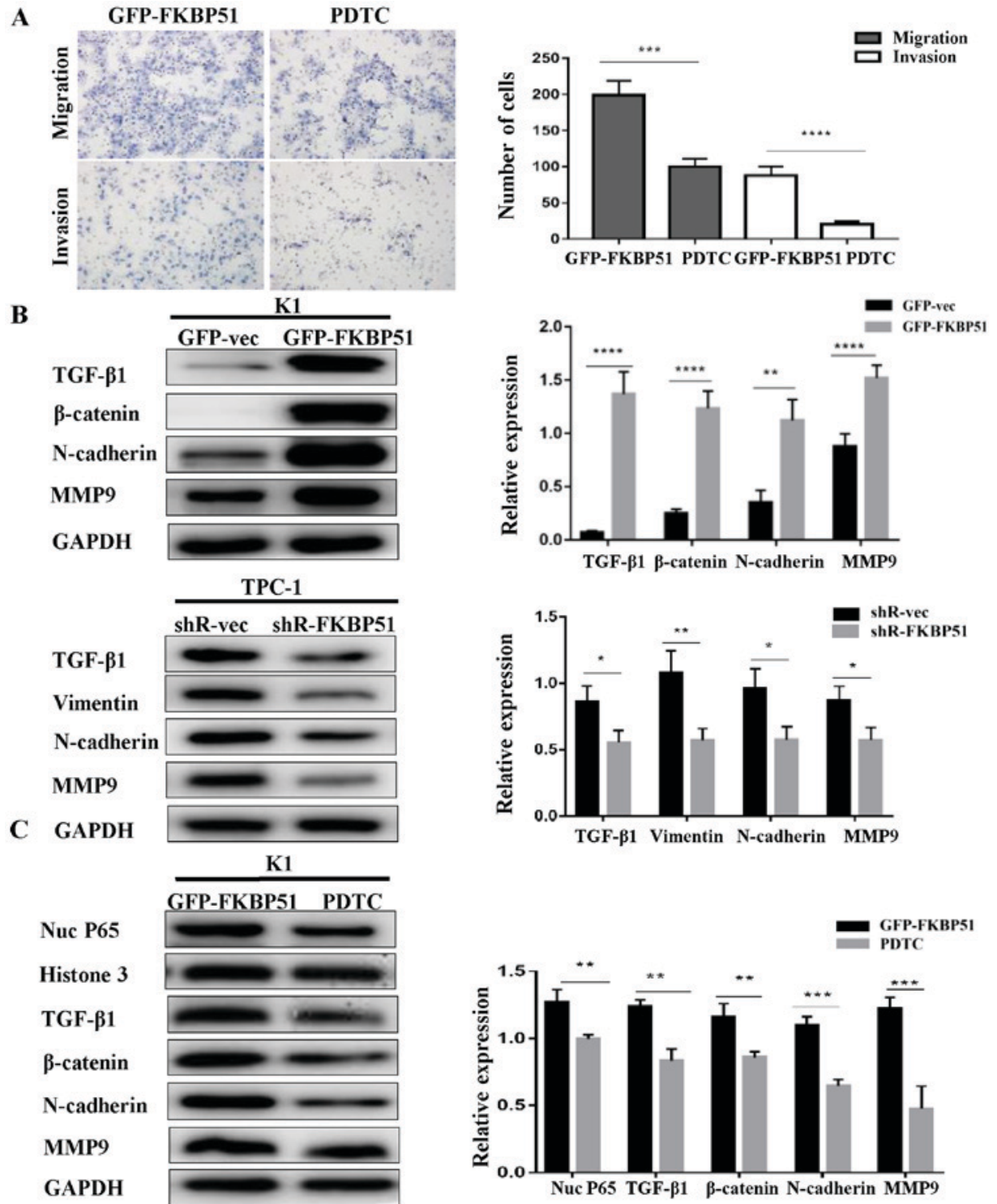

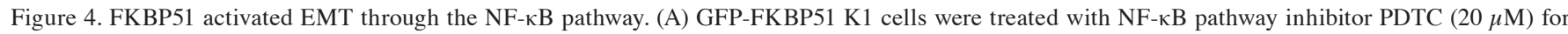
$24 \mathrm{~h}$ and the cells' migration and invasive capacities were determined using the transwell assay. (B) EMT-associated proteins TGF- $\beta 1, \beta$-catenin, $N$-cadherin, MMP9 of K1 cells and TGF- $\beta 1$, Vimentin, N-cadherin, MMP9 of TPC-1 cells were detected by western blotting. (C) FKBP51-overexpressing K1 cells were treated with NF-kB inhibitor PDTC ( $20 \mathrm{mM})$ for $24 \mathrm{~h}$ and expression of TGF- $\beta 1, \beta$-catenin, N-cadherin and MMP9 was compared with control group was detected. "P $<0.05 ;{ }^{* *} \mathrm{P}<0.01 ;{ }^{* * *} \mathrm{P}<0.001$. FKBP51, FK506 binding protein 51; GFP, green fluorescent protein; vec, vector; MMP, matrix metalloproteinase; EMT, epithelial mesenchymal transition.

K1

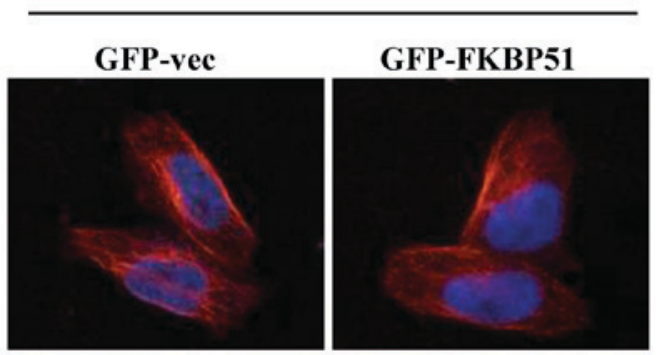

TPC-1

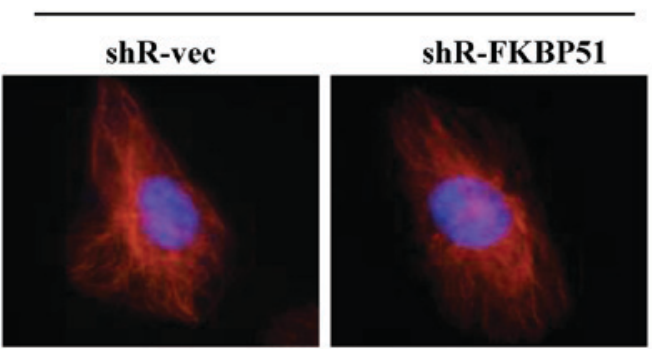

Figure 5. FK506 binding protein 51 does not alter the formation of tubulin. Immunofluorescence was used to detect the tubulin formation, and relative fluorescence intensity and distribution of tubulin revealed no significant difference $(\mathrm{P}>0.05)$. GFP, green fluorescent protein.

translocation of NF- $\mathrm{KB}$ in lung cancer. Lv et al (43) revealed that twist1 regulates EMT via the NF- $\kappa$ B pathway in PTC.
The present study also assessed whether FKBP51 is able to promote tubulin formation by using immunofluorescence, 
however no evidence of such an effect was identified. It was also assessed whether FKBP51 can promote tubulin formation by using immunofluorescence, however, once again no evidence of such an effect was observed.

To conclude, the present study demonstrates that FKBP51 promotes migration and invasion of PTC through the NF- $\kappa \mathrm{B}$ pathway and activation of EMT-associated genes, indicating its diagnostic and therapeutic value.

\section{Acknowledgements}

Not applicable.

\section{Funding}

The present study was supported by the National Natural Science Foundation of China (grant no. 31370897), and all the results come from the joint efforts of all authors.

\section{Availability of data and materials}

The datasets generated/analyzed during the present study are available from the corresponding author on reasonable request.

\section{Authors' contributions}

YG, RZ, EE, HY, SL, LS and YZ designed the study. YG, JD and MW performed the experiments. YG wrote the manuscript and analyzed the data.

\section{Ethics approval and consent to participate}

All patients provided written informed consent prior to their inclusion. The present study was approved by the Ethical Committee of Shandong Provincial Hospital.

\section{Patient consent for publication}

All patients provided written informed consent for the publication of their data.

\section{Competing interests}

The authors declare that they have no competing interests.

\section{References}

1. Dornan J, Taylor P and Walkinshaw MD: Structures of immunophilins and their ligand complexes. Curr Top Med Chem 3: 1392,2003

2. Cheung-Flynn J, Roberts PJ, Riggs DL and Smith DF: C-terminal sequences outside the tetratricopeptide repeat domain of FKBP51 and FKBP52 cause differential binding to Hsp90. J Biol Chem 278: 17388-17394, 2003.

3. Cheung J and Smith DF: Molecular chaperone interactions with steroid receptors: An update. Mol Endocrinol 14: 939-946, 2000.

4. Riggs DL, Roberts PJ, Chirillo SC, Cheung-Flynn J, Prapapanich V, Ratajczak T, Gaber R, Picard D and Smith DF: The Hsp90-binding peptidylprolyl isomerase FKBP52 potentiates glucocorticoid signaling in vivo. Embo J 22: 1158-1167, 2003.

5. Tai PK, Maeda Y, Nakao K, Wakim NG, Duhring JL and Faber LE: A 59-kilodalton protein associated with progestin, estrogen, androgen, and glucocorticoid receptors. Biochemistry 25: 5269-5275, 1986 .
6. Gallo LI, Ghini AA, Piwien Pilipuk G and Galigniana MD: Differential recruitment of tetratricorpeptide repeat domain immunophilins to the mineralocorticoid receptor influences both heat-shock protein 90-dependent retrotransport and hormone-dependent transcriptional activity. Biochemistry 46: 14044-14057, 2007.

7. Brucker SY, Eisenbeis S, König J, Lamy M, Salker MS, Zeng N, Seeger H, Henes M, Schöller D, Schönfisch B, et al: Decidualization is impaired in endometrial stromal cells from uterine rudiments in Mayer-Rokitansky-Küster-Hauser syndrome. Cell Physiol Biochem 41: 1083, 1097, 2017.

8. Leach DA, Trotta AP, Need EF, Risbridger GP, Taylor RA and Buchanan G: The prognostic value of stromal FK506-binding protein 1 and androgen receptor in prostate cancer outcome. Prostate 77: 185-195, 2017.

9. Hou J and Wang L: FKBP5 as a selection biomarker for gemcitabine and Akt inhibitors in treatment of pancreatic cancer. PLoS One 7: e36252, 2012.

10. Ni L, Yang CS, Gioeli D, Frierson H, Toft DO and Paschal BM: FKBP51 promotes assembly of the Hsp90 chaperone complex and regulates androgen receptor signaling in prostate cancer cells. Mol Cell Biol 30: 1243-1253, 2010.

11. Jiang W, Cazacu S, Xiang C, Zenklusen JC, Fine HA, Berens M, Armstrong B, Brodie C and Mikkelsen T: FK506 binding protein mediates glioma cell growth and sensitivity to rapamycin treatment by regulating NF-kappaB signaling pathway. Neoplasia 10: 235-243, 2008.

12. Solassol J, Mange A and Maudelonde T: FKBP family proteins as promising new biomarkers for cancer. Curr Opin Pharmacol 11: 320-325, 2011.

13. Storer CL, Dickey CA, Galigniana MD, Rein T and Cox MB: FKBP51 and FKBP52 in signaling and disease. Trends Endocrinol Metab 22: 481-490, 2011.

14. Pyo JS, Kang G, Kim DH, Chae SW, Park C, Kim K, Do Si, Lee HJ, Kim JH and Sohn JH: Activation of nuclear factor- $\kappa$ B contributes to growth and aggressiveness of papillary thyroid carcinoma. Pathol Res Pract 209: 228-232, 2013.

15. Wei L, Hui M, Sun D, Li W, Wang D, Zhang G and Tan J: The relationship between BRAFV600E, NF- $\kappa \mathrm{B}$ and $\mathrm{TgAb}$ expression in papillary thyroid carcinoma. Pathol Res Pract 213: 183-188, 2017.

16. Rotoli D, Morales M, Del Carmen Maeso M, Del Pino García M, Morales A, Ávila J and Martín-Vasallo P: Expression and localization of the immunophilin FKBP51 in colorectal carcinomas and primary metastases, and alterations following oxaliplatin-based chemotherapy. Oncol Lett 12: 1315-1322, 2016.

17. Romano S, D'Angelillo A, D'Arrigo P, Staibano S, Greco A, Brunetti A, Scalvenzi M, Bisogni R, Scala I and Romano MF: FKBP51 increases the tumour-promoter potential of TGF-beta. Clin Transl Med 3: 1, 2014.

18. D'Angelillo A, Staibano S, Russo M, Romano MF and Romano S: Molecular aspects of FKBP51 that enable melanoma dissemination. Curr Mol Pharmacol 9: 141-147, 2015.

19. Song IH, Kim KR, Lim S, Kim SH and Sung CO: Expression and prognostic significance of epithelial-mesenchymal transition-related markers and phenotype in serous ovarian cancer. Pathol Res Pract, 2018.

20. Ceresini G, Corcione L, Michiara M, Sgargi P, Teresi G, Gilli A, Usberti E, Silini E and Ceda GP: Thyroid cancer incidence by histological type and related variants in a mildly iodine-deficient area of Northern Italy, 1998 to 2009. Cancer 118: 5473-5480, 2012.

21. Jonklaas J, Murthy S, Liu D, Klubo-Gwiezdzinska J, Krishnan J, Burman KD, Boyle L, Carrol N, Felger E and Loh YP: Novel biomarker SYT12 may contribute to predicting papillary thyroid cancer outcomes. Future Sci OA 4: FSO249, 2017.

22. Derwahl M and Nicula D: Estrogen and its role in thyroid cancer. Endocr Relat Cancer 21: T273-T283, 2014.

23. Liu J, Chen G, Meng XY, Liu ZH and Dong S: Serum levels of sex hormones and expression of their receptors in thyroid tissue in female patients with various types of thyroid neoplasms. Pathol Res Pract 210: 830-835, 2014.

24. Amin MB, Greene FL, Edge SB, Compton CC, Gershenwald JE, Brookland RK, Meyer L, Gress DM, Byrd DR and Winchester DP: The Eighth Edition AJCC Cancer Staging Manual: Continuing to build a bridge from a population-based to a more "personalized" approach to cancer staging. CA Cancer J Clin 67: 93-99, 2017.

25. Haixia Guan, Zhongyan Shan, Xiaoyi Mi, et al: 11 years of pathological analysis of thyroid cancer before and after common salt iodization. J China Med Univer 35: 284-285, 2006. 
26. Zhang Q, Liu SZ, Zhang Q, Guan YX, Chen QJ and Zhu QY Meta-analyses of association between BRAF(V600E) mutation and clinicopathological features of papillary thyroid carcinoma. Cell Physiol Biochem 38: 763-776, 2016.

27. Chen GG, Vlantis AC, Zeng $Q$ and van Hasselt CA: Regulation of cell growth by estrogen signaling and potential targets in thyroid cancer. Curr Cancer Drug Targets 8: 367-377, 2008.

28. Choi MH, Moon JY, Cho SH, Chung BC and Lee EJ: Metabolic alteration of urinary steroids in pre- and post-menopausal women, and men with papillary thyroid carcinoma. BMC Cancer 11: 342, 2011.

29. Le Bihan S, Marsaud V, Mercier-Bodard C, Baulieu EE, Mader S, White JH and Renoir JM: Calcium/calmodulin kinase inhibitors and immunosuppressant macrolides rapamycin and FK506 inhibit progestin-and glucocorticosteroid receptor-mediated transcription in human breast cancer T47D cells. Mol Endocrinol 12: 986-1001, 1998.

30. Rotoli D, Morales M, Ávila J, Maeso MDC, García MDP, Mobasheri A and Martín-Vasallo P: Commitment of scaffold proteins in the onco-biology of human colorectal cancer and liver metastases after oxaliplatin-based chemotherapy. Int J Mol Sci 18: E891, 2017.

31. Luo K, Li Y, Yin Y, Li L, Wu C, Chen Y, Nowsheen S, Hu Q, Zhang L, Lou Z and Yuan J: USP49 negatively regulates tumorigenesis and chemoresistance through FKBP51-AKT signaling. EMBO J 36: 1434-1446, 2017.

32. Loercher A, Lee TL, Ricker JL, Howard A, Geoghegen J, Chen Z, Sunwoo JB, Sitcheran R, Chuang EY, Mitchell JB, et al: Nuclear factor-kappaB is an important modulator of the altered gene expression profile and malignant phenotype in squamous cell carcinoma. Cancer Res 64: 6511-6523, 2004

33. Romano S, Xiao Y, Nakaya M, D'Angelillo A, Chang M, Jin J, Hausch F, Masullo M, Feng X, Romano MF and Sun SC: FKBP51 employs both scaffold and isomerase functions to promote NF- $\kappa \mathrm{B}$ activation in melanoma. Nucleic Acids Res 43 6983-6993, 2015.

34. Li P, Zhang X, Wang L, Du L, Yang Y, Liu T, Li C and Wang C: lncRNA HOTAIR contributes to 5FU resistance through suppressing $\mathrm{miR}-218$ and activating NF- $\mathrm{B} / \mathrm{TS}$ signaling in colorectal cancer. Mol Ther Nucleic Acids 8: 356-369, 2017.

35. Stechschulte LA, Hinds TD Jr, Ghanem SS, Shou W, Najjar SM and Sanchez ER: FKBP51 reciprocally regulates GR $\alpha$ and PPAR $\gamma$ activation via the Akt-p38 pathway. Mol Endocrinol 28: 1254-1264, 2014.
36. Kim JY, An HJ, Kim WH, Gwon MG, Gu H, Park YY and Park KK: Anti-fibrotic effects of synthetic oligodeoxynucleotide for TGF- $\beta 1$ and smad in an animal model of liver cirrhosis. Mol Ther Nucleic Acids 8: 250-263, 2017.

37. Hu J, Zhu Q, Li PL, Wang W, Yi F and Li N: Stem cell conditioned culture media attenuated albumin-induced epithelial-mesenchymal transition in renal tubular cells. Cell Physiol Biochem 35: 1719-1728, 2015

38. Romano S, Staibano S, Greco A, Brunetti A, Nappo G, Ilardi G, Martinelli R, Sorrentino A, Di Pace A, Mascolo M, et al: FK506 binding protein 51 positively regulates melanoma stemness and metastatic potential. Cell Death Dis 4: e578, 2013.

39. Srivastava SK, Bhardwaj A, Arora S, Tyagi N, Singh AP, Carter JE, Scammell JG, Fodstad $\varnothing$ and Singh S: Interleukin-8 is a key mediator of FKBP51-induced melanoma growth, angiogenesis and metastasis. Br J Cancer 112: 1772-1781, 2015.

40. Takaoka M, Ito S, Miki Y and Nakanishi A: FKBP51 regulates cell motility and invasion via RhoA signaling. Cancer Sci 108: 380-389, 2017.

41. Ribeiro FR, Meireles AM, Rocha AS and Teixeira MR: Conventional and molecular cytogenetics of human non-medullary thy roid carcinoma: Characterization of eight cell line models and review of the literature on clinical samples. BMC Cancer 8: 371, 2008

42. Ying Y, Qingwu L, Mingming X, Zhenju S, Chaoyang T and Zhengang T: Emodin: One main ingredient of shufeng jiedu capsule reverses chemoresistance of lung cancer cells through inhibition of EMT. Cell Physiol Biochem 42: 1063-1072, 2017.

43. Lv N, Shan Z, Gao Y, Guan H, Fan C, Wang H and Teng W: Twist1 regulates the epithelial-mesenchymal transition via the NF- $\kappa$ B pathway in papillary thyroid carcinoma. Endocrine 51: 469-477, 2016

(i) (5) This work is licensed under a Creative Commons Attribution-NonCommercial-NoDerivatives 4.0 International (CC BY-NC-ND 4.0) License. 